\title{
THREATS OF ECONOMIC CRISES
}

\author{
MURMAN KVARATSKHELIA \\ Doctor of Economic sciences, Professor, \\ Academician of Academy Georgian \\ Economic Sciences, \\ Sokhumi State University, Georgia \\ murmankvara77@gmail.com
}

Abstract. The present article examines the historical aspects of the origin and development of various economic crises existing in the world, which constantly raises an issue of finding ways out of the problem, before scientists-researchers. In this regard, the author reviews the views of the representatives of the classical school of different epochs on the elimination of crises. In addition, the author also analyzes the directions proposed by modern scientists, the most notable of which is the theory of the real economic cycle as an independent direction, which laid the foundation for the systematic study of the economic crisis. Moreover, a conclusion that the slowdown in output growth in market conditions is not due to market inefficiency, but is due to low rates of technological development, and economic cycles are caused by technological shocks is notable. Based on the above assumption, scientists presented an argument, that the market can restore equilibrium without an outside intervention. The cyclical nature of crises followed by economic stimulus is also analyzed.

KEYWORDS: ECONOMIC THEORIES; GLOBAL FINANCIAL CRISES; PERFECT COMPETITION; STOCK EXCHANGES;

RATIONAL EXPECTATIONS; OVERPRODUCTION; DEFICIENCY.

For citation: Kvaratskhelia, M., (2020). Threts of Economic Crises. Globalization and Business, 10. 75-78. (In Georgian) https://doi.org/10.35945/gb.2020.10.009

\section{INTRODUCTION}

The development of the world economy is largely linked to the history of crises. Their not-so-rare periodicity has always led to the variability of economic cycles, thus giving some impetus to the emergence of new economic theories. The object of their research was cyclical fluctuations, which required the study of the underlying causes. This issue has become especially relevant in connection with the severe economic and financial crises in the world in the XX-XXI centuries. Crises of lesser severity and depth have been periodically observed over the centuries. Recently, this problem has become one of the most actual one for the global world. This was naturally followed by active reasoning and theorizing by economists. Their opinions often change and radically differ from each other.

\section{Genesis of economic crises}

If we rely on the traditional classical school crisis theory, the crises are temporary. This is due to the fact that the principle of market self-regulation operates in the conditions of perfect competition. At the same time, production generates its own demand and any sudden disproportion is automatically regulated thanks to flexible pricing. However, the perfection of the market is not permanent, which has been repeatedly convinced by economists. Therefore, most economists no longer rely on this theory. Modern American economist Anwar Sheikh even calls this economic orthodoxy the existence of a perfect market, perfect knowledge and expectations a perfect nonsense trio (Shaikh, 2007).

The followers of Marx had a radically different opinion from the classics. According to this theory, the main cause of the crisis is the existence of private property and the domination of the market system in competition, so the contradictory nature of the capitalist system. This is manifested in the misappropriation of publicly produced goods. According to the Marxist approach, capitalist economics is contradictory. It creates anarchy in the economy. Entrepreneurs have a vague real level of demand and have to operate under high risk conditions. The unpredictability of public demand, price volatility and the imperfection of the bar are the reasons for the crisis of overproduction (Arthur...et al 1969). These views are characterized by rather weak arguments in the theory of modern crises and it is impossible to rely on it.

Milton Friedman developed a monetary theory about crises and, in particular, the crisis of overproduction, thus naming the fluctuation of the bank interest rate as the main cause of the crisis. According to Friedman, when there is a crisis in the economy, it leads to a decrease in bank loans and, consequently, an increase in interest rates. As a result of the decline in cash flow, the crisis of overproduction begins.

Unlike Friedman, opinion of J. Keynes, even if the interest rate is reduced to zero, it is impossible to pull the economy out of the crisis, because the fate of the national economy is determined by the profit of entrepreneurs, not 
the interest rate ("liquidity trap"). According to Keynes, the economic cycle was driven by changes in aggregate demand and output. According to him, the change in aggregate demand / supply causes investment instability. The Keynesian model was widely used, and he based his reasoning on the need for protectionism in economics. However, events in the United States later cast doubt on Keynesian analysis. His theory could not answer the state that had developed in the 1980s Keynesian theory could not cope with high inflation. The stagnation outgrown into stagflation, and the correlation between the Phillips curve and the dependence on inflation and unemployment was also questioned. Friedman (1968) and Phillips $(1967,1968)$ later substantiated the link between unpredictable inflation and unemployment (Blanchard, 2011).

In addition to Keynes's work, the theory of insufficient consumption was reflected in the works of Hobson and Foster. In their opinion, a cycle is a breach of the balance between supply and demand. This theory is explained by the psychological characteristics of people, their propensity to save. Demand for the means of production is declining, followed by a drop in investment. Profit rate analysis is crucial in crisis research. Optimistic sentiments among the population and entrepreneurs during the economic boom increase optimistic expectations of capital gain. As a result, excessive optimism gives us economic development, reduction of loan interest, salary increase, etc. But this period is followed by a decline, during which optimism is replaced by pessimism and has the opposite effect. The interest rate rises and the profit rate tends to zero. Keynesians believe that at such times the state needs to pursue effective policies. Keynesian theory that cyclical fluctuations are caused by changes in consumption has been replaced by neoclassical "supply economics" due to its current inability.

In 1976, a new macroeconomic theory emerged that considered the behavior of firms and households in terms of rational expectations. The author of this theory is Robert Lucas, and he, unlike Keynes, who analyzes aggregate, macroeconomic indicators, focuses on microeconomic factors and studies them in detail. Lucas tried to prove that we can reach macroeconomic indicators through microeconomic analysis, but in fact it was very difficult to show and his theory came to a standstill.

In subsequent periods, developed theories related to human physiology. One of the first to develop this theory was Arthur Cecil Pigou. According to him, crises depend on the psychological state of the population: changes in pessimism and optimism cause waves of crises and booms in the economy.

The theory of innovation developed by Joseph Schumpeter and Hansen is based on the fact that significant scientific and technical changes are periodically introduced in the economy and as a result there is an overproduction of goods. Schumpeter's merit in the study of business cycles is quite large. He concluded from his research that the longterm cycle it includes short-term and medium-term cycles that affect each other, making it more difficult to predict the expected consequences of the crisis.
There are also many investment theories related to crises developed by Friedrich Hayek, Ludwig Mises and Dennis Robertson. According to this theory, the causes of the crisis in periods of economic growth can be excessive investment. Therefore, they consider the inadmissibility of economic booms as a way to fight crises, which requires an increase in interest rates during the period of economic prosperity. Later Nobel laureates Edward Prescott and Finn Cowland, with the development of real business cycle theory, aimed to overcome the complexity posed by the analysis of Lucas's theory. Their theory is based on assumptions of perfect competition and rational expectations, which were considered a few years earlier with the same assumptions. This was the first paper to build a model of real business cycles.

The theory of real business cycles was a completely new approach. Based on it, it has been argued that cycles can be studied by dynamic models of general equilibrium, and the business cycle model adequately characterizes the patterns of long-term economic growth. It became possible to formulate dynamic-stochastic models of total equilibrium.

Prescott and Culend can be considered "new classics" because they formulated the idea that all fluctuations have a balanced character. They, like the classics and unlike Keynes, consider state stabilization unnecessary in developed countries, since a large part of GDP is included in the equilibrium model and there is no need to include additional market equilibrium deviation parameters in the models.

The great merit of the creators of RBC models is that they were able to relate microeconomic and macroeconomic indicators, including establishing an organic link between them, based on assumptions of behavior rationality, optimal decision making, and the pursuit of profit maximization. An analysis of the causes of economic fluctuations in the RBC model shows that the largest share comes from technological shocks (75\%).

In conclusion, Prescott and Kydland developed the theory of the real economic cycle as an independent direction and laid the foundation for a systematic study of the economic crisis. Under market conditions, output growth slows down not because of market inefficiency but because of low rates of technological development, and economic cycles are caused by technological shocks. Based on this, they argued that the market can restore equilibrium without outside intervention.

Eventually, in their opinion, in most cases, technological change was considered to be the cause of the economic crisis in the context of a developed market economy.

Subsequent practice has proven that the RBC methodology has played an important role in the study of economic crises. However, the researchers adapted the model and renamed it ("Stochastic Dynamic General Equilibrium Macroeconomics"). The new model took into account the imperfections of the market and presented a more realistic analysis. With this move came the convergence of the views of the classics and the Keynesians.

In view the famous economist of modernity Olivier Blanchard, the financial sector plays an insufficient role in 
economic cycles. In his view, it is impossible to understand the causes of the crisis and its development trends without a financial mechanism. Blanchard's opinion has been confirmed by recent events. It is true that the financial sector depends on the real business, but the financial sector itself can deal a decisive blow to business processes through savings and risk redistribution.

It is well known that the financial sector occupies a large scale in today's market sector. It is quite a vulnerable field and can have a significant impact on the change of cyclical processes and the development of crises. However, this does not mean that the financial sector should be considered as the only cause of the crisis.

Practice has proven that the economic crisis, regardless of its originating causes, affects the entire economy. It is characterized by sharp and devastating manifestations and dramatically worsens the economic situation of the country and society. If we look at the history of crises in the world, we can say that the most severe and deepest crises took place in the recent period, $\mathrm{XX}-\mathrm{XXI}$ century (Samuelson\&Nordhaus, 20007: 886-887)

It is also known in the history of economic thought that the first crisis arose where capitalist relations first developed: in England in 1825. Once in 8-10 years from this time the crises were characterized by recurrence. They did not have a particularly sharp face and did not last for a long period of time, which eliminated the fluctuations in a short time.

It should be noted that the crises of the 19th century lasted for an average of two years and the decline in GDP was about $3 \%$. The next century saw an increase in the depth of the crisis and a sharp decline in GDP. Over time, the characteristics of the economic cycle began to change. The period between the crises has decreased considerably, if before the crises were accompanied by a drop in prices, now, on the contrary, prices and wages have started to rise in parallel with the crisis. The use of regulatory levers by state institutions has made it possible to stimulate the economy during a crisis and reduce the overheating of the economy during the boom.

It should be noted that crisis situations have less impact on innovative and high-tech industries. In addition, as the role of the service sector grows day by day, the role of capital is relatively diminishing, which has also reduced the duration of the crisis. A nature of the crises has shown that small and medium-sized businesses respond much more flexibly to fluctuations, while giants suffer more and more easily.

In the history of the world economy, the "Great Depression" of 1929-33 was particularly severe for mankind. His likeness has not been repeated before or since.

After World War II (1948-49), the United States experienced a crisis of overproduction, which was repeated in other countries in the following periods. In particular, in 1957-58, 1974-75, 1980-81, albeit with less severity. Considering the Keynesian theory and the Keynesian anticyclical policy of the government, the economies of the capitalist countries were stabilized.

At the same time, how paradoxical it is that the socialist countries were characterized by a crisis of shortage, which was due to bureaucracy and state ownership of the means of production. It was a system that was considered to hinder the development of the economy, although in the reports of the high echelons of the state government the rate of economic growth was far ahead of the developed countries. The natural processes of transformational development of the economy have slowly shifted most of the countries to a new set and the crisis of scarcity has been eliminated. This process began in the 90 s of the 20th century.

The recent severe financial crisis, which is even compared to the "Great Depression", occurred in 2008. Unemployment has risen sharply and states have had to spend trillions of dollars to avoid a major financial crash. The process turned out to be so large that the capitalist system and the truth of liberal approaches were called into question.

Since then, despite some stability, the financial crisis has re-emerged in a number of countries since 2011. Due to rising public debt and budget deficits in some European countries, some countries faced default, although in 2012 the situation improved in part thanks to EU financial assistance.

If we look at the history of crises, it appears that most of them started with a severe situation in the financial sector and then spread to the entire economy. The reason for them was considered by some economists to be the weakness of the state as a regulator. The first crisis in many countries has played a major role in accelerating the privatization process and private sector development.

The Great Depression of 1929-1933 was the longest, deepest, and most comprehensive crisis in the history of the world. It started in America and shook the whole world economic system. The severe recession was followed by the collapse of stock exchanges. The events that unfolded on the stock exchanges under the name of "Black Tuesday" have gone down in history. Unemployment in the US rose from $3.2 \%$ to $24.9 \%$ and it was only nine years later that it became possible to return to baseline.

There is still a debate among scholars-economists as to what caused such a large-scale depression. Of the many considerations, one is significant in the form of stock market crashes. However, according to $\mathrm{O}$. Blanchard, the crisis started before the stock market crash and was caused by other factors [8].

After the crisis of 2008, the correctness of the opinion of many scientists (Ch. Kindelberg, etc.) who studied the causes of the financial crisis became clear. Their analysis follows the following logic: based on positive expectations, investors start investing their free financial resources and this often turns into excess investment. Once economic agents find that the future is overly optimistic, the financial system shakes and may start to panic. Suddenly emerging financial "bubbles" burst. Kindelberg theory was not popular in the 1980s, although its validity has recently been proven. His theory is based on the Minsky model.

In the study of the instability characteristic of capitalism, it is important to note the contribution of Hyman Minsky (1919-1996), who considered the fragility of the global financial crisis and capitalism. He named the credit sector as the initial reason for the financial crisis. Minsky is considered 
post-Keynesian and it considered the control of all channels of credit expansion as the main task of economic policy. The reason for this was his view that the existence of private lending outside the bank further increases tax liabilities. In examining the shortcomings of capitalism as a system, Minsky concludes that as soon as measures are taken to avoid a crisis, it further increases the risks of a new crisis that may turn out to be more acute.

Hyman Minsky studied the psychology of economic agents, after which Charles Kindelberg developed a theory of the financial crisis based on his reasoning. Minsky says the precondition for the crisis will arise during the investment boom. The financial system is fundamentally fragile under capitalism. This is especially due to the complexity and diversity of financial instruments.

A financial crisis arises when companies need more cash than they can get. They are now looking for alternative ways of financing and liquidating market positions. This process is provocative of falling output and rising unemployment. Another factor causing the crisis is the high level of debt in the economy. Due to this, the instability in the financial sector is transferred to other areas and affects the whole economy.

Traditional monetary policy is impossible to get out of the financial crisis; it requires a strict system that accurately defines financial institutions. The function of the central bank should be in the role of writing off bad debts and preventing financial crisis. Hyman Minsky views have had many critics, especially because he did not explain the crisis accurately and did not formulate his concept specifically.

Based on the above, it is possible to male several conclusions, namely:

Crisis is a complex phenomenon and a significant shortcoming of the market economy. The causes of the crisis are multifaceted, though developed economic theories and accumulated practical experience make it possible to anticipate and avoid the expected crisis in the future.

Proper operation of the financial system and maximum risk insurance are essential for conducting the anti-crisis measures. At the same time, it is important for each country to take care of the strength of its real and financial sector, so as not to be vulnerable and painlessly endure and overcome the periods of crisis.

The recurring nature if the crisis cycles being reflected in the sudden global pandemic of the year of 2020 has virtually halted the functioning of the entire world economy and the problem of properly managing the economic and financial crisis was placed on the agenda.

The final outcome and consequences of the world's greatest crisis are still unknown. It goes without saying, that there is a need for maximum mobilization of Governments and central banks, coordination of fiscal and monetary policies and regulation if the banking system in order to prevent and eliminate the escalation of the crisis.

\section{REFERENCES}

Shaikh, A. (2007). Globalization and the myth of free trade. http://european.ge/.

Burns, Q. A. F. (1969. The Business Cycle in a Changing World, National Bureau of Economic Research.

Blanchard, O. (2011). Macroeconomics. Publishing TSU.

Finn, F. \& Edward, P. (2004). Contribution to Dynamic Macroeconomics: The Time Consistency of Economic Policy and the Driving Forces Behind Business Cycles, Advanced information on the Bank of Sweden Prize in Economic Sciences in Memory of Alfred Nobel, 11 October.

Mekvabishvili, E.,(2012) Modern Macroeconomic Theories. Tbilisi.

Papava, V. (2020). Coronomics and fundamentally new economic crisis. Economy and Crisis, 2.

Samuelson, P., \& Nordhaus W., (2000). Economics. Tbilisi.

Silagadze, A., (2010) Economic Doctrines. Tbilisi.

Bohoslavsky, J. P. \& Raffer, K. (2018): Sovereign Debt Crises

Cassis, Y., (2013): Crises and Opportunities: The Shaping of Modern Finance

Purica, I. (2015): Nonlinear Dynamics of Financial Crises

Gorton, G. B. \& Tallman, E. W. (2018): Fighting Financial Crises

Roy E. Allen (2016): Financial Crises and Recession in the Global Economy, Fourth Edition

https://www.youtube.com/watch?v=fGoB3T1kTW0. 